\title{
Flow rate measurements under sluice gates
}

\author{
Carlos Otero Silva ${ }^{1}$ and Manuel Rijo ${ }^{2}$
}

\author{
${ }^{1}$ Instituto Superior de Engenharia, Universidade do Algarve, Faro, Portugal (corresponding \\ author).E-mail: csilva@ualg.pt
}
${ }^{2}$ Hydraulic Professor, Escola de Ciências e Tecnologia, Universidade de Évora, Instituto de Ciências Ambientais Mediterrânicas, Portugal. E-mail: rijo@uevora.pt

\section{Abstract}

Sluice gates are commonly used in canals for control and measurement of the flow. The discharge under sluice gates can be determined through the Energy-Momentum Method (EM), the orifice flow rate equations and the application of the $\Pi$-theorem of the dimensional analysis. The different discharge methods available, for free and submerged hydraulic jump including the transition between flows, were compared with experimental data. The performance of the different calibration methods was analyzed. The test program was conducted in the laboratory flume and in the experimental irrigation canal of the University of Évora, Portugal. The test program shows that the evaluation of the discharge under sluice gates for free and submerged flows and for the transition between both flows through the methods based in the EM were those who had better results. For the studied gates openings, the results also show that the methods which consider the division of the submerged flow in partial and totally submerged did not improve the discharge results. 